\title{
From amino acids polymers, antimicrobial peptides, and histones, to their possible role in the pathogenesis of septic shock: a historical perspective
}

\author{
Isaac Ginsburg' \\ Peter Vernon van Heerden ${ }^{2}$ \\ Erez Koren' \\ 'Institute of Dental Sciences, Faculty \\ of Dental Medicine, The Hebrew \\ University of Jerusalem, ${ }^{2}$ General \\ Intensive Care Unit, Hadassah \\ University Hospital, Jerusalem, Israel
}

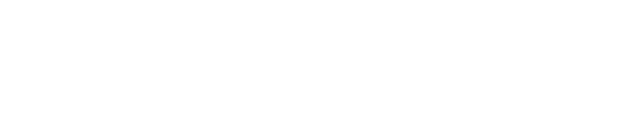

\begin{abstract}
This paper describes the evolution of our understanding of the biological role played by synthetic and natural antimicrobial cationic peptides and by the highly basic nuclear histones as modulators of infection, postinfectious sequelae, trauma, and coagulation phenomena. The authors discuss the effects of the synthetic polymers of basic poly $\alpha$ amino acids, poly L-lysine, and poly L-arginine on blood coagulation, fibrinolysis, bacterial killing, and blood vessels; the properties of natural and synthetic antimicrobial cationic peptides as potential replacements or adjuncts to antibiotics; polycations as opsonizing agents promoting endocytosis/phagocytosis; polycations and muramidases as activators of autolytic wall enzymes in bacteria, causing bacteriolysis and tissue damage; and polycations and nuclear histones as potential virulence factors and as markers of sepsis, septic shock, disseminated intravasclar coagulopathy, acute lung injury, pancreatitis, trauma, and other additional clinical disorders
\end{abstract}

Keywords: histones, sepsis, septic shock

\section{Introduction}

The pioneering work of Anton van Leeuwenhoek, Edward Jenner, Ignaz Semmelweiss, Louis Pasteur, Robert Koch, Elia Metchnikoff, and many others linked microbes with infectious diseases and helped establish the germ theory of disease. ${ }^{1}$ Robert Koch's postulates and Metchnikoff's phagocytosis theory described various functions of macrophages and their ability to kill microorganisms. This formed the basis for numerous studies on the biochemical properties and role in infection and immunity of phagocytic cells such as neutrophils and macrophages. These phagocytic cells are rich in antimicrobial peptides, lysosomal hydrolases, and oxidants. These early theories also lead to the discovery of proinflammatory cytokines and their role in microbial infections. However, the early discovery of lysozyme in 1923, and the further discovery of penicillin by Fleming, Florey, and Chane in 1928, was a major step in attempting to control severe microbial infections that may result in septic shock and organ failure; these conditions have a very high mortality even today. The recent concern regarding acquisition of antibiotic resistance by the microbe and the ongoing risk to life of the postinfectious sequelae prompted a very intense search for alternative antimicrobial cationic peptides to hopefully cope with severe microbial infections and their aftermath.

The basic concepts of microbial virulence were skillfully reviewed by Casadevall and Pirofski. ${ }^{2}$ They stated that "while the importance of a host's susceptibility for

\footnotetext{
Correspondence: Peter Vernon van Heerden

General Intensive Care Unit, Hadassah

Medical Center, PO Box 12000,

Jerusalem 9112001 , Israel

Tel + 972505172864

Email vernon@hadassah.org.il
} 
a microbe's virulence was often recognized, the existing definitions did not account for the contributions of both pathogen and host." As we know today, sepsis is indeed the host response (organ dysfunction) to invasion by pathogenic microorganisms (infection), while septic shock is the more extreme form of this host reaction where vasodilation and translocation of fluid from the vascular space to the interstitial space causes hypotension and other cellular and metabolic abnormalities. Casadevall and Pirofski ${ }^{2}$ reviewed historical concepts of microbial pathogenicity and virulence, proposed new definitions, and suggested a classification system for microbial pathogens based on their ability to cause damage as a function of the host's immune response. One typical example is septic shock (see section on "Can histone released from neutrophils" section).

This review will address the nature and role of histones as well as other modulators of infection and the host response to infection. Histones may be defined as highly basic proteins around which DNA coils to form chromatin. Their role in infection is described further.

\section{The effect of the synthetic polymers of basic of poly $\alpha$ amino acids poly L-lysine and poly L-arginine on blood coagulation, fibrinolysis, bacterial killing, and blood vessels}

Even as early as 1952-1956, teams of investigators at the Weitzman Institute of Science in Rehovot, Israel, headed by Ephraim Katchalski, were the first to synthesize and investigate the role of the linear polymers of basic amino acids such as poly L-lysine, poly L-arginine, and poly L-ornithine in the retardation of blood coagulation and fibrinolysis, killing of bacteria and mammalian cells, promotion of phagocytosis, and toxicity to blood vessels. ${ }^{3-9}$ It is of note that synthetic cationic polymers are actually histone mimics, sharing a high cationic charge capable of interaction with anionic agents. The researchers at Weizmann Institute also successfully explored the use of such poly amino acids as protein models and studied many of their physical, chemical, and biological properties. In all cases, the effects of the cationic polymers were abrogated by poly anions such as poly L-aspartic acid, poly L-glutamic acid, and the highly sulfated compound heparin..$^{3-9}$ Unfortunately, these pioneering "ancient" studies are hardly ever cited in the modern literature and may be lost to the clinicians forever.

The retardation of clot lysis by basic poly cations was reconfirmed in $2015 .{ }^{10,11}$ In sepsis, both coagulation (activation of the coagulation cascade) as well as fibrinolysis are enhanced. Therapeutic strategies (eg, activated protein C) have previously been directed at reducing clot formation in the microcirculation to reduce organ dysfunction in septic patients. The authors showed that histone mimics(poly L-lysine and poly L-arginine) and neutrophil extracellular traps exerted antifibrinolytic effects in a plasma environment and that the combination of histones and DNA also significantly prolonged clot lysis by forming thicker fibers accompanied by improved stability and rigidity. ${ }^{10-12}$

\section{The properties of natural and synthetic antimicrobial cationic peptides designed to replace antibiotics}

In 1956 and later on in 1958 and in 1960, poly L-lysine was shown to possess potent bactericidal effects against a variety of microorganisms and also against certain viruses, all abrogated by poly-anions such as heparin poly-glutamic and poly-aspartic acids. ${ }^{9,13,14}$ However, being toxic to mammalian cells, their clinical use should be considered with caution. ${ }^{15}$

Antimicrobial peptides (AMP) are mainly small peptides (12-50 amino acids) containing a positive charge and an amphipathic structure. The AMPs, which are rich in proline, tryptophan, arginine, lysine, or histidine, are actually mimics of nuclear cationic histones (see section on "Can histone released from neutrophils") and are able to interact with negatively charged microbial and mammalian membranes to disrupt the bilayer curvature, beyond a threshold concentration of membrane-bound peptide. In bacteria, AMPs rapidly interact with surface lipopolysaccharide (LPS) of Gram-negative organisms and with the membrane-associated lipoteichoic acid (LTA) in Gram-positive organisms, and they also demonstrate toxicity to a variety of mammalian cells. AMPs may also induce bacteriolysis.

Since 1956, an overabundance of publications focused on the chemistry, physics, biology, and bactericidal effects of a large variety of linear and nonlinear cationic AMPs. ${ }^{16-22}$ These cationic agents may be considered evolutionarily ancient weapons against microbial infections. They may also play a pivotal role in innate immunity and as agents for specific uses because of their natural antimicrobial properties and a low propensity for the development of bacterial resistance. Hopefully, one day, AMPs may provide an alternative to conventional antibiotics (discussed later).

Readers who require further background on this topic would be well-served spending time reading the works of and paying tribute to the pioneers: $M$ Zasloff, $\mathrm{R}$ Hancock, K Brogden, Y Shai, T Ganz, A Peschel, P Elsbach, Robert I 
Lehrer, JK Spitznagel, and many others, who were the ones to delve into the complicated chemistry, physics, and biological effects and possible future medical uses of AMPs.

\section{Polycations as opsonizing agents promoting endocytosis/phagocytosis}

In general, polycationic agents can interact via electrostatic forces with negatively charged sites, mainly on the surfaces of microbial and mammalian cells. Such interactions may perturb the membrane, induce cell agglutination, and also cause permeability changes that may lead to cell lysis. ${ }^{23}$ The attachment of cationic agents to surfaces of negatively charged particles is called opsonization and is similar to the effect of antibodies. Both facilitate the internalization (phagocytosis) of cationic particles by the professional phagocytic cells, neutrophils (PMNs), and macrophages, but surprisingly, also by nonprofessional phagocytes and by certain tumor cells. Although we will not fully cover the topic, it is worth mentioning that a variety of positively charged agents have also been shown to act as transfecting agents and as agents promoting the delivery of drugs as conjugates and as "decorators" of drug-loaded carriers. ${ }^{24}$

It is important to note that nonspecific plasma globulins and IgGs are positively charged macromolecules. However, nonspecific cationic globulins, which can bind to cell surfaces by electrostatic forces, might interfere with the binding of specific antibodies. Indeed, a thermostable cytotoxic factor, globulin, in normal human plasma inhibited the action of heterologous antibodies on HeLa cells. ${ }^{25}$

In 1986, it was shown that Entamoeba histolytica and Acanthamoeba palestinensis, two distinct classical phagocytic cells (possibly evolutional forefathers of neutrophils and macrophages), which stubbornly refused to internalize/engulf Candida albicans, nevertheless did so very avidly if precoated by arginine-rich polycations. ${ }^{26}$ These studies resulted in later experiments that showed phagocytosis-endocytosis of Candida albicans and of Group A Streptococci by mouse fibroblasts and by epithelial cells in culture. ${ }^{27}$ In this study, the most potent opsonins for Group A Streptococci were specific antibodies supplemented with complement, nuclear histone, poly lysine, poly arginine, ribonuclease, leukocyte lysates, leukocyte cationic proteins, and, to a lesser extent, cationic lysozyme and myeloperoxidase.

Highly cationic histone, RNAse, leukocyte extracts, and platelet extracts also functioned as opsonins for phagocytosis of streptococci in the peritoneal cavity. ${ }^{27}$ However, the phagocytic capabilities of mouse fibroblast poly karyons (cells with multiple nuclei) were much higher than those of ordinary spindle-shaped fibroblasts, probably due to their very large cytoplasmic area. Calf thymus histone also functioned as a good opsonic agent for the uptake of Candida by human fibroblasts, HeLa cells, epithelial cells, monkey kidney cells, and rat heart cells in culture. ${ }^{27}$ Phagocytosis of Streptococci and Candida by macrophages and the uptake of Candida by fibroblasts were both strongly inhibited by the polyanions hyaluronic acid, DNA, and dextran sulfate. The paucity of nonprofessional phagocytes of hydrolases capable of breaking down microbial cell wall components may contribute to the persistence of nonbiodegradable components of bacteria in tissues and lead to the perpetuation of chronic inflammatory sequelae such as granulomatosis. ${ }^{28}$

Two excellent, but concerning, examples of phagocytosis of microbes in vivo showed that Staphylococcus aureus, by forming microcolonies, could survive unharmed within skin keratinocytes, waiting for the opportunity to attack patients with low immunity. The mechanism of cell uptake was not disclosed. ${ }^{29,30}$

It was also demonstrated that nonbiodegradable cell wall components could persist for long periods within macrophages in arthritic granulomas. Another example is the chronicity of lesions in tuberculosis. ${ }^{31-33}$ Furthermore, macrophages and neutrophils loaded with opsonized streptococcal cell walls can be translocated to remote sites to induce chronic inflammation. ${ }^{34-36}$

\section{Polycations and lysozyme as activators of autolytic wall enzymes (muramidases) in bacteria, causing bacteriolysis and tissue damage}

The discovery of the bacteriolysis phenomenon dates back to $1893^{32,37}$ when Buchner ${ }^{37}$ reported that fresh serum was able to kill certain bacteria, an effect which was lost upon heating to $55^{\circ} \mathrm{C}$. He attributed the bactericidal action of serum to a heat-labile constituent that he called "alexine" (from Greek "to ward off"). One year later, Pfeiffer described the dissolution of Vibrio cholera by fresh serum of guinea pigs immunized with heated vaccine, which could be correlated with protection against infection in both passively and actively immunized animals. ${ }^{32}$

However, the significance of the biochemical degradation of microbes as related to tissue injury in inflammation, infection, and postinfectious sequelae has emerged mainly from a large series of investigations ${ }^{32,38,39}$ that focused on:

1. The structure and function of the bacterial cell walls

2. The role of muramidases (autolytic wall enzymes) in normal bacterial multiplication 
3. The role played by lysozyme, leukocyte-derived polycations, cationic enzymes, and antibiotics (mostly $\beta$-lactams) in bacteriolysis

4. The role of muramidase-deficient strains in pathology

5. Antibiotic resistance

6. Microbial killing and degradation:

The role of the cell wall components: LPS, LTA, and peptidoglycan (PPG) in the activation of leukocytes and in the generation of oxidants, proteinases, and cytotoxic cytokines.

7. The role of microbial cell wall components in the pathogenesis of granulomatous inflammation and in the potentiation of innate immunity to infections and of tumor-cell proliferation

Morphologically, two main patterns of bacterial cell degradation under various physiological and pathological conditions have been defined:

1. The term plasmolysis was proposed when a significant degradation of cytoplasmic constituents occurred, leaving apparently intact cell walls

2. The term bacteriolysis was proposed when a significant breakdown and degradation of the rigid cell walls, presumably due to the uncontrolled activation of autolytic wall enzymes (muramidases), occurred.

Bacteriolysis can be defined as an event that may occur when normal microbial multiplication is altered due to an uncontrolled activation of a series of autolytic cell-wall breaking enzymes (muramidases). It may happen following treatment of bacteria by $\beta$-lactam antibiotics or also by a large variety of bacteriolysis-inducing cationic peptides such as histones, elastase and cathepsin G, lysozyme, and PLA $_{2}$. When bacteriolysis occurs in vivo, cell wall- and membrane-associated LPS (endotoxin) from Gram-negative organisms and LTA and PPG from Gram-positive organisms are released. These highly phlogistic agents can act on macrophages to induce the generation and release of reactive oxygen and nitrogen species, cytotoxic cytokines, hydrolases, proteinases, and also activate the coagulation and complement cascades. ${ }^{40}$

Peptidoglycan hydrolysis can result in the rupture of the murein sacculus due to its high osmotic pressure, leading to the release of cytoplasmic constituents and cell wall fragments. ${ }^{32}$ A possible explanation for the long persistence of highly phlogistic nonbiodegradable microbial cell wall remnants within professional phagocytic cells was offered in $1989 .{ }^{41}$
It was proposed that following phagocytosis either by PMNs or by macrophages, the engulfed microorganisms are exposed intraphagosomally to the respiratory burst generating oxidants, LL-37, lysosomal cationic proteinases, and also numerous hydrolases, which inactivate the autolytic wall enzymes thus allowing the survival of highly phlogistic microbial cell wall component.

It was also shown that neutrophil-mediated myeloperoxidase, $\mathrm{H}_{2} \mathrm{O}_{2}$, and $\mathrm{HOCl}$ production inactivated a class of cytoplasmic membrane enzymes (penicillin-binding proteins [PBP's]) in Escherichia coli, Staphylococcus aureus, and Pseudomonas aeruginosa. These PBP's covalently bind $\beta$-lactam antibiotics to their active sites. This contributed to the persistence of nondegraded microbial components, leading to unbalanced bacterial growth and cell death. ${ }^{42,43}$

Degradation of Staphylococcus aureus by $\beta$-lactams was markedly inhibited by the polyanions suramine and Evans blue, suggesting that accumulation of polyanions and sulfated polysaccharides in inflammatory sites might also interfere with bacteriolysis. ${ }^{44,45}$

Clindamycin treatment of Staphylococcus aureus caused a remarkable thickening of the bacterial cell wall due to increased numbers of O-acetyl groups in the murein, which made the bacterial wall much more resistant to lytic enzymes within bone marrow-derived macrophages, and this was revealed by electron microscopy and radiolabeling experiments. This reduced wall degradation might increase the survival of highly phlogistic walls in inflammatory sites. Furthermore, such clindamycin-treated bacteria were ingested by adherent bone marrow-derived macrophages at a higher rate than untreated bacteria. ${ }^{46}$ The involvement of bacteriolysis in sepsis was also reported. ${ }^{47}$

\section{The lysozyme riddle: is this enzyme a genuine and an effective bacteriolytic enzyme?}

In 1922, Alexander Fleming discovered the enzyme lysozyme ( $N$-acetylmuramide glycanhydrolase). ${ }^{48}$ Lysozyme is a 139-amino acid cationic protein found in neutrophils, macrophages, saliva, mucous, egg white, milk, and additional body fluids. Patients with myeloid leukemia can be diagnosed by measuring lysozyme in urine by a simple method using suspensions of Micrococcus lysodeikticus as a highly sensitive substrate (Ginsburg, unpublished data). Lysozyme was anticipated to kill, lyse, and biodegrade pathogenic microorganisms.

Lysozymecan very rapidly (within $1-2$ minutes) lyse certain nonpathogenic Gram-positive cocci (eg, Micrococcus 
lysodeikticus and also spore-bearing aerobic bacilli) possessing a "simple" PPG. However lysis of Staphylococcus aureus, which possesses a more complex PPG, can take up to 6-12 hours. It is of clinical significance that lysozyme rarely induces lysis either of hemolytic Streptococci, Streptococcus viridans, Listeriae, Mycobacteria, or Candida species, and it lyses enteric bacteria Staphylococcus aureus slowly. It could, however be partially lysed by a synergism between lysozyme, lysolecithin and phospholipase C. ${ }^{32}$ Also, hemolytic streptococci cultivated in the presence of subinhibitory concentrations of penicillin lost their membrane-associated phospholipids to a large extent following treatment with small concentrations of lysothelin and lysozyme. ${ }^{32}$

The main reason for the relative resistance to lysozyme action of Staphylococcus aureus and perhaps also of the majority of pathogenic microorganisms, may be ascribed to the presence in their peptidoglycans of O-acetyl groups, which hinder the interaction of lysozyme with the $N$-acetylglucosamine- $N$-acetyl muramic acid linkages in the PPG. ${ }^{32,49,50}$ However, mild alkaline solutions rendered such cell walls digestible by egg-white lysozyme. ${ }^{51}$

The lack of deacetylating enzymes in phagocytes may explain why apparently intact Staphylococcal, Streptococcal, and Mycobacterial cell walls may persist for long periods either within phagolysosomes of macrophages in culture or also in vivo. However, lysozyme does not seem to function as a muramidase but rather as a cationic peptide that activates the microbial autolytic wall enzymes in certain bacteria. ${ }^{32}$ Usually, this process takes hours and is therefore missed when the bactericidal effects of AMP are tested for very short periods and expressed as colony forming units. ${ }^{49-52}$

Lysis of bacteria by antibiotics in vivo may also be involved in sepsis and septic shock (see section on "Can histone released from neutrophils" ${ }^{47}$ ).

\section{Synergistic effects among cationic peptides}

It was also demonstrated that mammalian cationic peptides from different structural classes (eg, $\alpha$-helical cationic peptides such as lactoferrin and most amphipathic membraneactive AMPs) frequently show synergy with each other and also with lysozyme. It is assumed that this reflects the cooperative interactions of the peptides with the outer membranes of Gram-negative bacteria and/or cooperative interaction with lipid bilayers in general. It was concluded that, given the substantial diversity of peptides in any given location in the host, synergistic interactions are an important determinants of the overall effectiveness of the peptides. ${ }^{52}$ Cationic peptides and cationic proteins can also act in synergy with reactive oxygen species to injure mammalian cells. ${ }^{53-56}$

\section{Can histone released from neutrophil nets function as a major virulence factor involved in the pathophysiology of septic shock trauma and also in many additional clinical disorders?}

It is alarming that today clinicians are still limited when trying to treat the life-threatening sequelae of severe microbial infections, which very often lead to sepsis and septic shock, both of which have a high mortality. ${ }^{57,58}$

The annual incidence of sepsis in the USA has been estimated to affect as many as 750,000 hospitalized patients with mortality reaching about $40 \%{ }^{57,58}$ Worldwide, sepsis is one of the commonest, deadliest disease entities, and globally, 20 to 30 million patients are estimated to be afflicted every year with what is one of the least well-understood disorders.

Screening the voluminous literature on sepsis treatments reveals the repeated unsuccessful efforts to save patients' lives by administering antibiotics, sometimes combined with only singly-selected antagonists. The numbers of unsuccessful antisepsis agents that have been tested in clinical trials in the last 30 years is phenomenal, and today, even the most promising agent, activated protein $\mathrm{C}$, has been recently removed from use. Today, there is no specific effective treatment for sepsis and septic shock. ${ }^{57,58}$

The pioneering studies on poly alpha cationic amino acids $^{3-9}$ and their role as bactericidal agents, as opsonins, and as bacteriolysis-inducing agents, (see the earlier sections) raised interest regarding the possible role of histones and modified histones, actually lysine and arginine-rich peptides, in the pathophysiology of a variety of clinical disorders.

This "new field" of research emerged in 2009 from two "breakthrough" articles by $\mathrm{Xu}$ et $\mathrm{al}^{59}$ and Chaput et $\mathrm{al}^{60}$ in Nature Medicine. These authors had proposed that nuclear histones released from PMN nets may be the main cause of death in sepsis and that this is due to the toxicity of the highly cationic protein to endothelial cells (ECs).

Histones comprise five groups of nuclear proteins rich in the highly basic amino acids L-lysine and L-arginine, which are bound to chromatin in the cell nucleus. Extracellular histones are highly toxic to bacteria and to mammalian cells and can increase plasma thrombin generation by impairing endothelial thrombomodulin-dependent protein $\mathrm{C}$ activation, which is responsible for disseminated intravascular 
coagulopathy (DIC). Dysregulation of ECs by the released histones leads to a severe immune cytokine storm and coagulation cascade. The toxic effects of histones could be abrogated or slowed down by antibodies to histoneactivated protein $\mathrm{C}$ (a protease which cleaves histone) and also by heparin. Extracellular histones are also elevated in response to traumatic injury, and this elevation correlates with fibrinolysis ${ }^{6,10-12}$ and activation of anticoagulants. In trauma patients, an increase in histone levels between the time of admission and 6 hours is predictive of mortality. This suggests a possible role for activated protein $\mathrm{C}$ in mitigating the sterile inflammatory response after trauma through the proteolysis of circulating histones. However, the question of whether histones alone are the real culprits or just markers of cell damage is still unsettled.

Septic shock was recently redefined as a multifactorial synergistic phenomenon/disorder. While no distinct virulence factor (alarmin) has been identified, if successfully neutralized, the devastating immune responses can be slowed down or even stopped, which will hopefully reduce mortality. ${ }^{61,62}$

\section{The possible role of histones in additional clinical disorders}

The interesting publications regarding the possible pathogenetic properties of histones in sepsis has resulted in a plethora of studies, also suggesting that these circulating polycations may be involved in the pathogenesis of DIC, acute lung injury, trauma, pancreatitis, liver, renal and myocardial disorders, trauma, heat stroke, and many other clinical disorders. ${ }^{63-79}$ Analyzing these articles, one wonders if the presence of histones in the circulation indicates that these are innate virulence/toxic agents or just an additional marker of tissue damage.

\section{Can histones function alone in vivo as absolute virulence factors?}

It was previously demonstrated that the toxicity of histone to ECs and to epithelial cells in culture was markedly further enhanced (in a synergistic manner) in combination with oxidants, proteinases, and additional proinflammatory agents generated by activated neutrophils..$^{54,55,62,80,81}$ Such synergistic phenomenon might actually be a general mechanism of cell injury mediated by activated phagocytes recruited to infectious and inflammatory sites.

The following scenario might be depicted: following adherence to ECs, PMNs undergo NETosis, and the released DNA combined with histones is accompanied by activation of NADPH oxidase and generation of reactive oxygen species.
This happens concomitantly with activation of a large array of proinflammatory agents.

Dysregulation of ECs leads to platelets activation and the generation of cytokine storms and coagulation cascades.

However, it is highly plausible that in vivo, histones and additional toxic polycations (eg, LL-37, elastase) most probably never act on their own but always in synergism with many additional proinflammatory agents. ${ }^{54,55,81}$

Since histones' action could be abrogated either by antibodies to histone, activated protein $\mathrm{C}$, anionic heparin, and also additional polysulfates, it is reasonable to assume that these inhibitors actually affect not only histones action alone but also the synergism among the various agents. Therefore, if these inhibitors are administered early enough, they could still manage to neutralize the toxic effects to prevent the ongoing deleterious immune and coagulation responses.

Perhaps we could also use antioxidants, ${ }^{82}$ since NETos and the release of histones (from activated PMNs adhering to endothelial cells) are accompanied by the activation of the respiratory burst in PMNs. ${ }^{82}$

Years ago it was suggested that a multi-faceted approach to sepsis was required and not treatment based on a single antagonist, this paper was largely ignored. ${ }^{83}$

\section{Why is the mortality from sepsis still so high? \\ Current clinical management of sepsis}

Currently, most efforts in the clinical management of septic patients are directed at early recognition and diagnosis, prompt commencement of treatment, source control of sepsis, and early antibiotic therapy. Following this initial therapy, the rest of the therapeutic armamentarium is based on supportive treatment such as optimal fluid therapy, vasopressor and inotropic therapy, and organ support (eg, mechanical ventilation and renal replacement therapy). In light of our growing understanding of the underlying mechanisms of sepsis and the host response to sepsis, these treatments are directed at "downstream" processes that occur long after the initial injury.

Usually, in clinical practice, sepsis patients showing the main symptoms of tachypnea, tachycardia, confusion, high lactate and procalcitonin levels, leukocytosis or leucopenia arrive in the intensive care unit (ICU) many hours or even days, after developing symptoms. Therefore, even the "miracle" novel nonanticoagulant heparin ${ }^{81,84}$ combined with antibiotics might already be ineffective since by that time all the pathological biochemical processes are already well established. As for the nature of additional sepsis 
markers, which may be helpful in the early diagnosis of sepsis, the reader is directed to excellent review articles on the subject. ${ }^{61,82,85-89}$

Finally, taken together, it is not understood why the latest consensus definition of clinical of sepsis $2016^{90}$ has not considered and discussed either the possible involvement in sepsis of histones and additional cationic peptides, the use of nonanticoagulant heparin, ${ }^{84}$ oor the role of bacteriolysis in pathogenicity.

It seems that antihistone measures as a plausible and accepted therapy (see section on "Can histone released from neutrophils") have not yet matured sufficiently to reach practicing clinicians.

It is hoped that further studies on the pathophysiology of sepsis might shed more light on the possible validity of combinations of nonanticoagulant heparin, anti-inflammatory cocktails, anti-cytokines, antioxidants, and anti-bacteriolysis agents in the treatment of sepsis. To do so effectively, we have to define and employ very early markers of sepsis. ${ }^{81-85}$

\section{Looking to the future}

Consider a still hypothetical idea that every office of a public/private practitioner (a house doctor) may have available a simple, inexpensive kit to detect early sepsis makers to identify abnormal levels of biochemical, blood, and leukocyte parameters in urine, blood, or other biological fluid. These will replace the more cumbersome and expensive ELISA kits that, today, are usually available in research laboratories but not in the ICU. Thus, sepsis diagnosis will be much faster and more responsive to adequate effective treatment.

\section{Summary}

Taken together, our understanding of the possible role of highly charged polymers of basic amino acid in the pathophysiology of infection, in postinfectious and inflammatory sequelae, and following trauma and inflammation has evolved over more than 60 years and is still going on. Septic shock and posttrauma syndromes are considered synergistic multifactorial disorders where not a single virulence factor had been identified, which, if successfully inhibited, might delay or stop the immunological and coagulation cascades leading to a patient's demise. Circulating histones are also tied up with the pathogenesis of pulmonary, renal, cardiac, pancreatic, and liver disorders, as well as in other disorders. Today, we still do not fully know whether histones and additional cationic peptides released into the circulation are major virulence factors or just biomarkers of tissue damage.
Whatever the reasons are for the pathogenicity of polycations, the newly described nonanticoagulant heparin, if combined in time with antibodies to histones, activated protein C (a protease, which cleaves histones), nonbacteriolytic antibiotics, antioxidants, steroids, and cocktails of additional antagonists, may be justified for use as a therapeutic regimen. This may finally bring to an end the numerous unsuccessful trials of sepsis conducted, by the administration of single antagonists, over so many years in an attempt to cope with the patient's morbidity and unfortunate mortality. ${ }^{79}$ However, we should also consider the fact that since patients suspected of developing septic shock may usually arrive at the ICU hours or days after the appearance of symptoms, even antihistone strategies may not be fully protective by that time. Therefore, efforts should be made to identify novel, very early markers of tissue damage to allow early treatment.

The complexity of the sepsis syndrome, which involves multiple interactions among biochemical, immunological, and coagulation cascades, and the difficulty in identifying the disorders early enough are still the main stumbling blocks to achieve a consensus of how to prevent and treat the post infectious sequelae of sepsis and posttrauma syndromes.

\section{Disclosure}

Erez Koren is currently employed at Teva Pharmaceuticals Ltd, Israel. The authors report no other conflict of interests in this work.

\section{References}

1. Nelson KE, Williams CF, Masters Williams C. Early history of infectious disease: epidemiology and control of infectious diseases. Infect Dis Epidemiol. 2007:3-23.

2. Casadevall A, Pirofski LA. Host-pathogen interactions: redefining the basic concepts of virulence and pathogenicity. Infect Immun. 1999;67:3703-3713.

3. Katchalski E. Poly- $\alpha$-amino acids. Adv Protein Chem. 1951;6:123-185.

4. De Vries A, Schwager A, Katchalski E. The action of some water-soluble poly- $\alpha$-amino-acids on blood clotting. Biochem J. 1951;49:10.

5. Katchalski E, Bichovski-Slomnitzki L, Volcani B. Action of some watersoluble poly- $\alpha$-amino-acids on bacteria. Nature. 1952;169:1095-1096.

6. Ginsburg I, De Vries A, Katchalski E. The action of some water-soluble poly- $\alpha$-amino acids on fibrinolysis. Science. 1952;116:15-16.

7. Biezunski N, Shafrir E, De Vries A, Katchalski E. The action of polylysine on the conversion of fibrinogen into fibrin by coagulase thrombin. Biochem J. 1955;59:55.

8. Stein O, De Vries A, Katchalski E. The effect of polyamino acids on the blood vessels of the rat. Arch Int Pharmacodyn Ther. 1956;107:243-253.

9. Bichowsky-Slomnicki L, Berger A, Kurtz J, Katchalski E. The antibacterial action of some basic amino acid copolymers. Arch Biochem Biophys. 1956;65:400-413.

10. GouldTJ,LysovZ,Liaw PC. Extracellular DNA and histones: double-edged swords in immunothrombosis. J Thromb Haemost. 2015;13(Suppl 1): S82-S91.

11. Varjú I, Longstaff C, Szabó L, et al. DNA, histones and neutrophil extracellular traps exert anti-fibrinolytic effects in a plasma environment. Thromb Haemost. 2015;113:1289-1298. 
12. Longstaff C, Varju I, Sotonyi P, et al. Mechanical stability and fibrinolytic resistance of clots containing fibrin, DNA, and histones. J Biol Chem. 2013;288:6946-6956.

13. Hirsch JG. Bactericidal action of histone. J Exp Med. 1958;108:925-944.

14. Buchanan-Davidson DJ, Seastone CV, Stahmann MA. Action of synthetic polylysine on the growth and phagocytosis of bacteria in vitro. J Bacteriol. 1960;80:590-594.

15. Ginsburg I, Koren E. Are cationic antimicrobial peptides also "doubleedged swords?" Expert Rev Anti Infect Ther. 2008;6:453-462.

16. Phoenix DA, Dennison SR, Harris F. Antimicrobial peptides. Hoboken, NJ: John Wiley \& Sons; 2012.

17. Guaní-Guerra E, Santos-Mendoza T, Lugo-Reyes SO, Terán LM. Antimicrobial peptides: general overview and clinical implications in human health and disease. Clin Immunol. 2010;135:1-11.

18. Seo MD, Won HS, Kim JH, Mishig-Ochir T, Lee BJ. Antimicrobial peptides for therapeutic applications: a review. Molecules. 2012;17: 12276-12286.

19. Kang SJ, Park SJ, Mishig-Ochir T, Lee BJ. Antimicrobial peptides: therapeutic potentials. Expert Rev Anti Infect Ther. 2014;12:1477-1486.

20. Aoki W, Ueda M. Characterization of antimicrobial peptides toward the development of novel antibiotics. Pharmaceuticals (Basel). 2013;6: $1055-1081$.

21. Wang G, Mishra B, Lau K, Lushnikova T, Golla R, Wang X. Antimicrobial peptides in 2014. Pharmaceuticals (Basel). 2015;8:123-150.

22. Wang S, Zeng X, Yang Q, Qiao S. Antimicrobial peptides as potential alternatives to antibiotics in food animal industry. Int $J$ Mol Sci. 2016;17:603.

23. Antohi S, Brumfeld V. Polycation-cell surface interactions and plasma membrane compartments in mammals. Interference of oligocation with polycationic condensation. Z Naturforsch C. 1984;39:767-775.

24. Koren E, Torchilin VP. Cell-penetrating peptides: breaking through to the other side. Trends Mol Med. 2012;18:385-393.

25. Ginsburg I, Dishon T, Bloch M, Gross J. A thermostable cytotoxic factor in normal human serum active against landschutz ascites tumor cells. Exp Biol Med. 1961;107:235-240.

26. Ginsburg I, Mor N, Resnick M, Bercovier H. Polycationic agent facilitates endocytosis of microorganisms by amoebae. Eur J Cell Biol. 1986;41:130-133.

27. Ginsburg I, Sela MN, Morag A, et al. Role of leukocyte factors and cationic polyelectrolytes in phagocytosis of group A streptococci and Candida albicans by neutrophils, macrophages, fibroblasts and epithelial cells. Inflammation. 1981;5:289-312.

28. Stein H, Yarom R, Levin S, Dishon T, Ginsburg I, Harris TN. Chronic self-perpetuating arthritis induced in rabbits by a cell-free extract of group A streptococci. Proc Soc Exp Biol Med. 1973;143:1106-1112.

29. von Eiff C, Becker K, Metze D, et al. Intracellular persistence of Staphylococcus aureus small-colony variants within keratinocytes: a cause for antibiotic treatment failure in a patient with Darier's disease. Clin Infect Dis. 2001;32:1643-1647.

30. Mempel M, Schnopp C, Hojka M, et al. Invasion of human keratinocytes by Staphylococcu aureus and intracellular bacterial persistence represent haemolysin-independent virulence mechanisms that are followed by features of necrotic and apoptotic keratinocyte cell death. $\mathrm{Br}$ J Dermatol. 2002;146:943-951.

31. Ginsburg I. Can chronic and self-perpetuating arthritis in the human be caused by arthrotropic undegraded microbial cell wall constituants? A working hypothesis. Rheumatol Rehabil. 1977;16:141-149.

32. Ginsburg I. The role of bacteriolysis in the pathophysiology of inflammation, infection and post-infectious sequelae. APMIS. 2002;110:753-770.

33. Ginsburg I, Fligiel SE, Kunkel RG, Riser BL, Varani J. Phagocytosis of Candida albicans enhances malignant behavior of murine tumor cells. Science. 1987;238:1573-1575.

34. Ginsburg I, Gallis HA, Cole RM. Group A streptococci: localization in rabbits and guinea pigs following tissue injury. Science. 1969;166:1161-1163.

35. Ginsburg I, Trost R. Localization of group A streptococci and particles of titanium dioxide in arthritic lesions in the rabbit. J Infect Dis. 1971;123:292-296.
36. Rickles N, Zilberstein Z, Kraus S, Arad G, Kaufstein M, Ginsburg I. Persistence of group A streptococci labeled with fluorescein isothiocyanate in inflammatory sites in the heart and muscle of mice and rabbits. Proc Soc Exp Biol Med. 1969;131:525-530.

37. Buchner H. Über den Einfluß der Neutralsalze auf Serum-alexine, Enzyme, Toxalbumine, Blutkörperchen und Milzbrandsporen. Arch Hyg (Berl). 1893:138-178.

38. Ginsburg I. Cationic polyelectrolytes: a new look at their possible roles as opsonins, as stimulators of respiratory burst in leukocytes, in bacteriolysis, and as modulators of immune-complex diseases (a review hypothesis). Inflammation. 1987;11:489-515.

39. Ginsburg I. Bactericidal cationic peptides can also function as bacteriolysis-inducing agents mimicking beta-lactam antibiotics?; it is enigmatic why this concept is consistently disregarded. Med Hypotheses. 2004;62:367-374.

40. Ginsburg I. Role of lipoteichoic acid in infection and inflammation. Lancet Infect Dis. 2002;2:171-179.

41. Ginsburg I. Bacteriolysis is inhibited by hydrogen peroxide and by proteases. Agents Actions. 1989;28:238-242.

42. Rakita RM, Rosen H. Penicillin-binding protein inactivation by human neutrophil myeloperoxidase. J Clin Invest. 1991;88:750-754.

43. Hand WL, Hand DL, King-Thompson NL. Antibiotic inhibition of the respiratory burst response in human polymorphonuclear leukocytes. Antimicrob Agents Chemother. 1990;34:863-870.

44. Wecke J, Franz M, Giesbrecht P. Inhibition of the bacteriolytic effect of beta-lactam-antibiotics on Staphylococcus aureus by the polyanionic drugs suramin and Evans Blue. APMIS. 1990;98:71-81.

45. Wecke J, Lahav M, Ginsburg I, Kwa E, Giesbrecht P. Inhibition of wall autolysis of staphylococci by sodium polyanethole sulfonate "liquoid". Arch Microbiol. 1986;144:110-115.

46. Wecke J, Johannsen L, Giesbrecht P. Reduction of wall degradability of clindamycin-treated staphylococci within macrophages. Infect Immun. 1990;58:197-204

47. Periti P, Mazzei T. Antibiotic-induced release of bacterial cell wall components in the pathogenesis of sepsis and septic shock: a review. J Chemother. 1998;10:427-448.

48. Fleming A. On a remarkable bacteriolytic element found in tissues and secretions. Proc R Soc Lond (Biol). 1922;93:306-317.

49. Laible NJ, Germaine GR. Bactericidal activity of human lysozyme, muramidase-inactive lysozyme, and cationic polypeptides against Streptococcus sanguis and Streptococcus faecalis: inhibition by chitin oligosaccharides. Infect Immun. 1985;48:720-728.

50. Bera A, Herbert S, Jakob A, Vollmer W, Götz F. Why are pathogenic staphylococci so lysozyme resistant? The peptidoglycan O-acetyltransferase OatA is the major determinant for lysozyme resistance of Staphylococcu aureus. Mol Microbiol. 2005;55:778-787.

51. Wellman-Labadie O, Picman J, Hincke MT. Comparative antibacterial activity of avian egg white protein extracts. Br Poult Sci. 2008;49(2):125-132.

52. Yan H, Hancock RE. Synergistic interactions between mammalian antimicrobial defense peptides. Antimicrob Agents Chemother. 2001;45:1558-1560.

53. Ginsburg I, Kohen R. Synergistic effects among oxidants, membrane-damaging agents, fatty acids, proteinases, and xenobiotics: killing of epithelial cells and release of arachidonic acid. Inflammation. 1995;19:101-118.

54. Ginsburg I, Mitra RS, Gibbs DF, Varani J, Kohen R. Killing of endothelial cells and release of arachidonic acid. Synergistic effects among hydrogen peroxide, membrane-damaging agents, cationic substances, and proteinases and their modulation by inhibitors. Inflammation. 1993;17:295-319.

55. Ginsburg I, Kohen R. Invited review: cell damage in inflammatory and infectious sites might involve a coordinated "Cross-Talk" among oxidants, microbial haemolysins and ampiphiles, cationic proteins, phospholipases, fatty acids, proteinases and cytokines (An Overview). Free Radic Res. 1995;22:489-517.

56. Ginsburg I. Could synergistic interactions among reactive oxygen species, proteinases, membrane-perforating enzymes, hydrolases, microbial hemolysins and cytokines be the main cause of tissue damage in infectious and inflammatory conditions? Med Hypotheses. 1998;51:337-346.

57. Opal SM. The current understanding of sepsis and research priorities for the future. Virulence. 2014;5:1-3. 
58. Opal SM, Dellinger RP, Vincent JL, Masur H, Angus DC. The next generation of sepsis trials: what's next after the demise of recombinant human activated Protein C? Crit Care Med. 2014;42:1714.

59. Xu J, Zhang X, Pelayo R, et al. Extracellular histones are major mediators of death in sepsis. Nat Med. 2009;15:1318-1321.

60. Chaput C, Zychlinsky A. Sepsis: the dark side of histones. Nat Med. 2009; 15:1245-1246.

61. Ginsburg I, Koren E, Feuerstein O. Is bacteriolysis in vivo a friend or a foe? Relation to sepsis, chronic granulomatous inflammation and to oral disorders: an overview hypothesis. SOJ Microbiol Infect Dis. 2015;3(1):1-8

62. Koren E, Ginsburg I. Synergistic aspects to explain the pathophysiology of sepsis and septic shock-an opinion. J Infect Dis Ther. 2015;3(6):254

63. Chong W, Li Y, Liu B, et al. Anti-inflammatory properties of histone deacetylase inhibitors: a mechanistic study. J Trauma Acute Care Surg. 2012;72:347-353; discussion 53-54.

64. Li Y, Liu Z, Liu B, et al. Citrullinated histone H3: a novel target for the treatment of sepsis. Surgery. 2014;156:229-234

65. Zhao T, Li Y, Liu B, et al. Histone deacetylase inhibitor treatment attenuates coagulation imbalance in a lethal murine model of sepsis. Surgery. 2014;156:214-220.

66. Li Y, Liu Z, Liu B, et al. Citrullinated histone H3-A novel target for treatment of septic shock. J Surg Res. 2014;186:581.

67. Alam HB, Li Y. Citrullinated Histone H3 (Cit H3) in Septic Shock. Google patents United states patent US 20140057829 A1; 2012 Feb 1.

68. Chen R, Kang R, Fan XG, Tang D. Release and activity of histone in diseases. Cell Death Dis. 2014;5:e1370.

69. Alhamdi Y, Toh $\mathrm{CH}$. The role of extracellular histones in haematological disorders. Br J Haematol. 2016;173:805-811.

70. Kutcher ME, Xu J, Vilardi RF, Ho C, Esmon CT, Cohen MJ. Extracellular histone release in response to traumatic injury: implications for a compensatory role of activated protein C. J Trauma Acute Care Surg. 2012; 73:1389-1394.

71. Zhang H, Villar J, Slutsky AS. Circulating histones: a novel target in acute respiratory distress syndrome? Am J Respir Crit Care Med. 2013; 187:118-120.

72. Saffarzadeh M, Juenemann C, Queisser MA, et al. Neutrophil extracellular traps directly induce epithelial and endothelial cell death: a predominant role of histones. PLoS One. 2012;7:e32366.

73. Zhang Y, Wen Z, Guan L, et al. Extracellular histones play an inflammatory role in acid aspiration-induced acute respiratory distress syndrome. Anesthesiology. 2015;122:127-139.

74. Ward PA, Grailer JJ. Acute lung injury and the role of histones. Transl Respir Med. 2014;2:1.
75. Bosmann M, Grailer JJ, Ruemmler R, et al. Extracellular histones are essential effectors of C5aR-and C5L2-mediated tissue damage and inflammation in acute lung injury. FASEB J. 2013;27:5010-5021.

76. Ojima M, Yamamoto N, Hirose T, et al. Presence of neutrophil extracellular traps in bronchial aspirate of patients diagnosed with acute respiratory distress syndrome or acute exacerbation of idiopathic pulmonary fibrosis. Crit Care. 2015;19:1.

77. Huang H, Evankovich J, Yan W, et al. Endogenous histones function as alarmins in sterile inflammatory liver injury through Toll-like receptor 9 in mice. Hepatology. 2011;54:999-1008.

78. Abrams ST, Zhang N, Manson J, et al. Circulating histones are mediators of trauma-associated lung injury. Am J Respir Crit Care Med. 2013; 187:160-169.

79. Xu Z, Huang Y, Mao P, Zhang J, Li Y. Sepsis and ARDS: The Dark Side of Histones. Mediators Inflamm. 2015;2015:205054.

80. Ginsburg I, Gibbs DF, Schuger L, et al. Vascular endothelial cell killing by combinations of membrane-active agents and hydrogen peroxide. Free Radic Biol Med. 1989;7:369-376.

81. Ginsburg I, Koren E, Varani J, Kohen R. Nuclear histones: major virulence factors or just additional early sepsis markers? A comment. Inflammopharmacology. 2016:1-3.

82. Faix JD. Biomarkers of sepsis. Crit Rev Clin Lab Sci. 2013;50:23-36.

83. Ginsburg I. Multi-drug strategies are necessary to inhibit the synergistic mechanism causing tissue damage and organ failure in post infectious sequelae. Inflammopharmacology. 1999;7:207-217.

84. Wildhagen KC, Garcia de Frutos P, Reutelingsperger CP, et al. Nonanticoagulant heparin prevents histone-mediated cytotoxicity in vitro and improves survival in sepsis. Blood. 2014;123:1098-1101.

85. Reinhart K, Bauer M, Riedemann NC, Hartog CS. New approaches to sepsis: molecular diagnostics and biomarkers. Clin Microbiol Rev. 2012;25:609-634.

86. Kibe S, Adams K, Barlow G. Diagnostic and prognostic biomarkers of sepsis in critical care. J Antimicrob Chemother. 2011;66(Suppl 2): ii33-ii40.

87. Smith K, Bigham MT. Biomarkers in pediatric sepsis. Open Inflamm J. 2011;4:24-30

88. Cao Z, Robinson RA. The role of proteomics in understanding biological mechanisms of sepsis. Proteomics Clin Appl. 2014;8:35-52.

89. Almyroudis N, Grimm M, Davidson B, Rohm M, Urban C, Segal B NETosis and NADPH oxidase: at the intersection of host defense, inflammation, and injury. Front Immunol. 2013;4:45.

90. Singer M, Deutschman CS, Seymour CW, et al. The Third International Consensus Definitions for Sepsis and Septic Shock (Sepsis-3). JAMA 2016;315:801-810.
Journal of Inflammation Research

\section{Publish your work in this journal}

The Journal of Inflammation Research is an international, peer-reviewed open access journal that welcomes laboratory and clinical findings on the molecular basis, cell biology and pharmacology of inflammation including original research, reviews, symposium reports, hypothesis formation and commentaries on: acute/chronic inflammation; mediators of

\section{Dovepress}

inflammation; cellular processes; molecular mechanisms; pharmacology and novel anti-inflammatory drugs; clinical conditions involving inflammation. The manuscript management system is completely online and includes a very quick and fair peer-review system. Visit http://www.dove press.com/testimonials.php to read real quotes from published authors. 